\title{
Endocrine and Metabolic Manifestations of Tuberculosis
}

\author{
Madhuri Patil \\ Dr Patil's Fertility and Endoscopy Clinic, Bangalore, India
}

DOI: https://doi.org/10.17925/USE.2020.16.2.88

$\mathrm{T}$ uberculosis (TB) is a communicable disease caused by Mycobacterium tuberculosis bacilli, and is a major health concern in low- and middle-income countries (LMICS). Though classically seen as pulmonary disease, extrapulmonary TB, affecting various organs and other systems, is not uncommon. Endocrine gland involvement in $\mathrm{TB}$, as seen in the pre-antibiotic era, has markedly reduced in recent years with the availability of effective anti-TB therapy. Although rare, TB of endocrine glands, such as the adrenals, thyroid, and pituitary have pathophysiologic effects that are clinically significant. The thymus, parathyroid, pancreas, pineal gland, and gonads are other endocrine glands which may be affected by TB. The most commonly involved is the adrenal gland, and TB is an important cause of Addison's disease in LMICS. The thyroid gland is rarely involved and thyroid dysfunction is uncommon. Hypothalamic-pituitary dysfunction due to intracranial tuberculoma or tuberculous meningitis has also been reported. Involvement of the endocrine glands can also be a part of severe disseminated or miliary TB. Diagnosis of endocrine gland involvement in TB is a great clinical challenge and therefore a high index of suspicion must prompt one to investigate the patient thoroughly. A high prevalence of diabetes mellitus among patients with TB and likewise an incidence of TB among patients with diabetes, are both matters of concern in developing countries. It is now known that, even in the absence of direct gland involvement, the tuberculous disease process and/or anti-TB treatment can result in endocrine and metabolic derangements. Metabolic abnormalities like hyponatremia and hypercalcemia are also seen with TB. Both tuberculous involvement of endocrine glands as well as secondary metabolic and endocrine complications due to the disease need to be identified appropriately, as they may need some early supportive care. Endocrine TB and its complications usually respond well to current anti-tuberculous therapy. Hormonal therapy or specific interventions may be necessary only occasionally for correction of endocrine dysfunction.

\section{Keywords}

Tuberculosis, adrenal/thyroid/pituitary dysfunction, diabetes mellitus, anti-tuberculosis treatment

Disclosure: Madhiru Patil has no financial or non-financial relationships or activities to declare in relation to this article.

Acknowledgment: The authors gratefully acknowledge help from

Dr Rashmi Dalvi, Sr Consultant Pediatric Hematologist Oncologist, Bombay Hospital Institute of Medical Sciences, Mumbai, India, for providing data on sequalae of pediatric tuberculosis affecting hypothalamus and pituitary and restructuring the article to shorten it; Dr Vikrant Ghatnatti, Consultant Endocrinologist, I N Medical College, Belagavi, India for verifying Table 1 and proving valuable inputs; and Dr Jyoti M Nagmoti Professor of Microbiology, I N Medical College, Belagavi, India for verifying Table 3.

Review Process: Double-blind peer review.

Compliance with Ethics: This article involves a review of literature and does not report on new clinical data, or any studies with human or animal subjects performed by any of the authors.

Authorship: The named author meets the criteria of the International Committee of Medical Journal Editors for authorship for this manuscript, takes responsibility for the integrity of the work as a whole and has given final approval for the version to be published.

Access: This article is freely accessible at

touchENDOCRINOLOGY.com @ Touch Medical Media 2020

Received: June 15, 2020

Accepted: July 24, 2020

Published Online: December 17, 2020

Citation: US Endocrinology. 2020;16(2):88-96

Corresponding Author: Madhuri Patil, Dr Patil's Fertility and Endoscopy Clinic Bangalore, No. 1, Uma Admirality, First floor, Bannerghatta Road, Bangalore 560029, Karnataka, India. E: drmadhuripatil59@gmail.com

Support: No funding was received in the publication of this article.
Tuberculosis (TB) is a major public health concern in low- and middleincome countries (LMICS) of Asia and Africa, which have a high burden of human immunodeficiency virus (HIV) infection and malnutrition. It is epidemic in these regions being associated with high rates of morbidity and mortality. ${ }^{1}$ Though, TB incidence is declining at about $2 \%$ per year globally these regions still have many high TB burden countries. ${ }^{2}$

TB typically affects the lungs in adults, with a predilection to the upper lobes and varied manifestations. Extrapulmonary TB is usually secondary to pulmonary TB. Children are more likely to have primary complex TB, TB lymphadenitis, central nervous system TB, and when compounded with malnutrition, the miliary form of TB. Though uncommon, involvement of endocrine glands may be a part of disseminated infection or miliary TB or seen in patients with previous history of TB, involving either the lung, bones, joints, intestines, or genitourinary tract. In recent times the incidence of endocrine involvement has been low due to effective anti-TB therapy.

In most patients, overt endocrine manifestations are unusual and infrequent. One must be vigilant for these endocrinopathies in the presence of risk factors, namely previous TB, HIV infection, history of immunosuppressive treatment, hemodialysis, gastrectomy, jejunoileal bypass, or diabetes. In many instances, endocrine abnormalities do not always reflect direct infection of the gland, but may be the result of a physiological response or a consequence of therapy for TB. The most commonly involved endocrine glands in TB are the adrenals followed by pituitary, and hypopituitarism due to intracranial tuberculoma or tuberculous meningitis has been reported. ${ }^{3}$ Thyroid and other endocrine glands are less commonly affected. TB also imparts a cytokine-mediated 
Table 1: Diagnostic tests for extrapulmonary tuberculosis

\begin{tabular}{|c|c|}
\hline Imaging & Specific tests available for diagnosis \\
\hline Ultrasound & $\begin{array}{l}\text { Direct tests } \\
\text { - Acid-fast bacilli staining } \\
\text { - } \text { Culture methods } \\
\text { - Histopathology } \\
\text { - Molecular tests - nucleic acid } \\
\text { amplification tests }\end{array}$ \\
\hline Magnetic resonance imaging & $\begin{array}{l}\text { Indirect tests } \\
\text { - Immunological tests } \\
\text { - } \text { Serological tests }\end{array}$ \\
\hline Computerized tomography scan & \\
\hline
\end{tabular}

immuno-inflammatory state with altered immune-endocrine response, which has an impact on clinical and metabolic status as well as innate and adaptive immune response to Mycobacterium tuberculosis. ${ }^{4}$

Absence of overt symptoms and signs is a challenge to diagnosis; however, if suspected, magnetic resonance imaging (MRI), computerized tomography (CT), and CT-guided biopsy, with histopathology and microbiological testing should be done (Table 1). Specific tests include acid-fast bacilli detection, culture sensitivity and nucleic acid amplification tests (Table 1). ${ }^{5}$ The advantages and limitations of the diagnostic tests are elaborated in Table $2 .{ }^{6}$

The mainstay of modern therapy for TB is anti-TB treatment. Table 3 highlights the first-, second-, and third-line drugs with their dosage regimes. ${ }^{7} \mathrm{~A}$ combination of first-line antibiotics is used for treatment and is usually given for a period of 6-9 months. The treatment regimen consists of an initial 2-month treatment phase of four drugs followed by a continuation phase of two drugs for either 4 or 7 months (Table 4).,7 Second- and third-line drugs may be required for multidrug-resistant TB or extensively drug-resistant TB. ${ }^{2}$ Once a TB treatment regimen is initiated, it is important to assess and ensure adherence to therapy. Inadequate treatment can lead to failure to respond, persistent infectivity, development of drug resistance, and disease recurrence. It is important to monitor the patient for adverse reactions and response to treatment to determine efficacy and drug resistance. Endocrine and metabolic abnormalities do not always manifest with symptoms and signs but may require anti-tuberculosis therapy or specific interventions. The aim of the review is to identify both the direct and indirect impact of $M$. tuberculosis infection on endocrine glands and metabolic function so that when suspected we could diagnose and treat these.

\section{Search methods}

An electronic literature search was performed in PubMed Medline (1966-2020) using search terms "endocrine and metabolic aspects of tuberculosis", "adrenal insufficiency", "thyroid dysfunction", "pituitary dysfunction", "disorders of calcium and vitamin d metabolism", "diabetes mellitus". A total of 221 articles was retrieved. Appropriate cross references were then manually searched.

\section{Tuberculosis of the adrenal gland}

TB accounts for about 7-20\% of cases of Addison's disease. ${ }^{9}$ Five percent of the patients with disseminated TB develop clinically significant adrenal insufficiency and the incidence is higher in $\mathrm{LMICS} .{ }^{10} \mathrm{Adrenal}$ involvement is reported in $6 \%$ of cases in an autopsy series. ${ }^{11}$ TB infection of the adrenal gland is a result of hematogenous spread of the infection, most likely from pulmonary or genitourinary tract infection. ${ }^{12}$ No active extra-adrenal TB is seen in about $12 \%$ of patients with adrenal TB. ${ }^{13}$

Adrenal TB is often asymptomatic, and clinical features due to deficiency of production of glucocorticoids, mineralocorticoids, and androgens, appear only at a later stage, when more than $90 \%$ of the gland has been destroyed. ${ }^{14}$ Patients usually present with vomiting, diarrhea, generalized weakness, hyper-pigmentation, malaise, anorexia, weight loss, and postural hypotension. A history of either active TB elsewhere or a positive tuberculin skin test, may suggest a possibility of adrenal gland TB. Adrenal insufficiency in TB, in most cases, is due to direct involvement of the adrenal gland, which may initially be enlarged with extensive epithelioid granulomas and caseation, but as the disease progresses, with fibrosis it may become normal or smaller in size..$^{15}$ Calcification is evident in about $50 \%$ of cases. ${ }^{16}$ At times, the adrenal gland can be enlarged in pulmonary TB without adrenal involvement, possibly related to stress cortisol response and inflammation. ${ }^{14}$

\section{Diagnosis}

Recent improvements in imaging techniques and endocrinologic assays for adrenal function have provided greater insight into adrenal involvement in TB. Investigations usually reveal hyponatremia with hyperkalemia, low serum cortisol, and elevated serum adrenocorticotropic hormone levels diagnostic of Addison's disease. An 8 am fasting cortisol level of $<3 \mathrm{mcg} / \mathrm{dl}$ (83 nmol/l) suggests adrenal insufficiency. Cosyntropin or adrenocorticotropic hormone stimulation test is the most specific test for diagnosing adrenal insufficiency. ${ }^{17}$

On imaging, unilateral or bilateral non-calcified adrenal enlargement is seen on CT scan with active infection. Areas of lucency reflecting caseous necrosis with peripheral rim enhancement may be demonstrated with contrast-enhancement. ${ }^{18-21}$ Atrophy and calcification is usually seen in chronic infection, with shrunken adrenal glands, calcific areas, and irregular margins. However, CT scans often do not provide a definitive diagnosis. ${ }^{18} \mathrm{~A}$ cold abscess may result in a mass effect on imaging, with similar findings noted on MRI scans; however, calcifications in chronic cases are better seen on CT scans. MRI findings include hypointense or isointense areas on T1- and hyperintense areas on T2-weighted images. There are limited data available on positron emission tomography scans; however, one study has reported fluorodeoxyglucose enhancement similar to malignant lesions. ${ }^{22}$

A microbiological sample and tissue biopsy may be needed to rule out other causes of adrenal enlargement, such as malignancy, hemorrhage, fungal infection, amyloidosis, sarcoidosis, adenoma, hemangioma, and hyperplasia. CT-guided needle biopsy will help in confirming the diagnosis by the presence of caseating or noncaseating granulomas with glandular enlargement, adrenal destruction due to inflammation, or adrenal atrophy and fibrosis in chronic infection. ${ }^{11}$ Epithelioid granulomas are less frequent than in extra-adrenal foci, reflecting local production of anti-inflammatory steroids. ${ }^{23}$ Though calcification of adrenal gland is common, it is not a specific finding. Molecular diagnosis with culture-sensitivity of aspirated material for $M$. tuberculosis is diagnostic; however, specimens may not always be positive (Table 2).

\section{Management}

The drugs used and the standard anti-TB treatment regimen are as highlighted in Tables 4 and 5, and these are generally safe and well 
Table 2: Advantages and limitations of the specific tests for diagnosis of extrapulmonary tuberculosis

\begin{tabular}{|c|c|c|}
\hline Test & Advantages & Limitations \\
\hline AFB staining & Can identify AFB by Ziehl-Neelsen staining & $\begin{array}{l}\text { - Poor sensitivity (requires }>10,000 \text { bacilli/ml in tissue or fluid specimens to } \\
\text { give a positive result) } \\
\text { - Positive predictive value of } 10 \% \\
\text { - Not species specific }\end{array}$ \\
\hline Histopathology & $\begin{array}{l}\text { Quick, easy and cost-effective to detect } \\
\text { characteristic tubercular caseous granuloma with } \\
\text { epithelioid cells }\end{array}$ & $\begin{array}{l}\text { - } \text { Poor sensitivity (requires }>10,000 \text { bacilli/ml in tissue) } \\
\text { - High false negativity } \\
\text { - } \text { Technical difficulties } \\
\text { o Inability to get adequate sample } \\
\text { o Incorrect timing of sample collection } \\
\text { - Inadequate granuloma formation due to endometrial shedding } \\
\text { - Bacteriologically mute lesions }\end{array}$ \\
\hline $\begin{array}{l}\text { Tissue culture: Lowenstein- } \\
\text { Jensen culture }\end{array}$ & No specific advantages & $\begin{array}{l}\text { - Poor sensitivity (requires }>1,000 \text { bacilli/ml of specimen) } \\
\text { - Takes } 2-6 \text { weeks for the growth }\end{array}$ \\
\hline Tissue culture: BACTEC/MGITTM & $\begin{array}{l}\text { - Shorter turn-around time of } 2 \text { weeks } \\
\text { - Hold in time of } 6 \text { weeks minimum before } \\
\text { reporting negative result }\end{array}$ & $\begin{array}{l}\text { - Requires } 10-100 \text { bacilli/ml of specimen } \\
\text { - } \text { Phased out due to biosafety issues }\end{array}$ \\
\hline Nucleic acid amplification tests & $\begin{array}{l}\text { - High sensitivity (requires 1-10 bacilli/ml of } \\
\text { - } \text { - High specimen) } \\
\text { - Good reproducibility } \\
\text { - Rapid test }\end{array}$ & $\begin{array}{l}\text { - Limited Use due to high cost and requirement of a suitable infrastructure } \\
\text { - Low sensitivity }{ }^{2} \\
\text { - High specificity }{ }^{2} \\
\text { - Low positive predictive value } \\
\text { - False positivity of } 20 \% \\
\text { - Does not distinguish between viable and non-viable organisms }\end{array}$ \\
\hline GeneXpert ${ }^{\circledR}$ MTB/RIF & $\begin{array}{l}\text { - } \quad \text { Positive predictive value: } 66.7 \% \\
\text { - } \text { Negative predictive value: } 97.7 \% \text { (for } \\
\text { extrapulmonary specimens) }\end{array}$ & $\begin{array}{l}\text { - Affected by humidity and heat } \\
\text { - Detects non-viable bacteria }\end{array}$ \\
\hline $\begin{array}{l}\text { Single tube nested reverse } \\
\text { transcription PCR }\end{array}$ & $\begin{array}{l}\text { - Ability to detect live organisms } \\
\text { - Phenotypic drug susceptibility testing can be } \\
\text { done }\end{array}$ & $\begin{array}{l}\text { Needs to be transported in ice to the laboratory within } 2 \text { hours to prevent } \\
\text { degradation of RNA }\end{array}$ \\
\hline Multigene PCR & $\begin{array}{l}\text { Overcomes limitations, such as false positivity by } \\
\text { way of contaminations, false negativity, dead bacilli, } \\
\text { and asymptomatic TB of different sites }\end{array}$ & Positive in $59 \%$ of suspected cases \\
\hline \multicolumn{3}{|c|}{ Immunological tests for antibody detection } \\
\hline TST & May have some role in the pediatric cases & \multirow[b]{2}{*}{$\begin{array}{l}\text { - Incapable of distinguishing between latent TB Infection and active disease } \\
\text { - Low specificity } \\
\text { - Cross-reactivity with non-tuberculous mycobacteria } \\
\text { - } \text { activity of TB disease } \\
\text { - Do not provide data on drug susceptibility } \\
\text { - Negative IGRA or TST cannot be used alone to exclude the diagnosis of active } \\
\text { TB }\end{array}$} \\
\hline $\begin{array}{l}\text { IGRAS: QuantiFERON-TB Gold } \\
\text { and T-SPOT }{ }^{\circledR} \text { TB test }\end{array}$ & $\begin{array}{l}\text { Moderate to strong association between test } \\
\text { positivity and subsequent risk of active TB during } \\
\text { follow-up }\end{array}$ & \\
\hline $\begin{array}{l}\text { Serological (humoral antibody- } \\
\text { mediated) tests }\end{array}$ & - & $\begin{array}{l}\text { - Not recommended } \\
\text { - Have inconsistent estimates of sensitivity and specificity } \\
\text { - For extrapulmonary TB, there are no studies on commercial tests of sufficient } \\
\text { quality to enable their use }\end{array}$ \\
\hline
\end{tabular}

AFB = acid-fast bacilli; IGRA = interferon-gamma release assay; $M T B=M$. tuberculosis; $P C R=$ polymerase chain reaction; $R I F=$ rifampicin; $T S T=$ tuberculin skin test.

tolerated. For acute adrenal insufficiency, initial management involves administration of intravenous hydrocortisone (50-100 mg) every 6 hours, followed by maintenance doses of oral steroids at 15-20 mg per day. ${ }^{24}$ Most common oral steroids used are hydrocortisone or prednisone. ${ }^{24}$ Oral steroids are given three times daily, with the distribution of dose as follows: $10 \mathrm{mg}$ in the morning, $5 \mathrm{mg}$ at lunch time, and $5 \mathrm{mg}$ in the early evening-corresponding to the circadian rhythm. ${ }^{25-27}$ Patients on anti-TB therapy may need a higher dose of oral steroids, as rifampicin induces the cytochrome P450 enzyme system, causing increased metabolism of glucocorticoids. ${ }^{28}$ Adrenal crisis may result if steroid replacement therapy is inadequate. ${ }^{29}$ Mineralocorticoid therapy is also essential in Addison's disease. Adrenal size and function improve if anti-TB therapy is started early in the course of the disease, before its destruction. ${ }^{30}$ In patients where adrenal gland destruction is substantial, treatment will reduce adrenal gland size, but may not result in full recovery of adrenal function. ${ }^{29}$ 
Table 3: Drugs and dosage of first-, second-, and third-line anti-tuberculosis drugs

\begin{tabular}{|c|c|}
\hline Drug & Dose \\
\hline \multicolumn{2}{|l|}{ First-line drugs } \\
\hline Isoniazid & 5 mg/kg/day or 300 mg/day \\
\hline Rifampicin & 10 mg/kg/day or 600 mg/day \\
\hline Ethambutol & $25 \mathrm{mg} / \mathrm{kg} / \mathrm{day}$ \\
\hline Pyrazinamide & 25 mg/kg/day \\
\hline Streptomycin & 15 mg/kg/day 5-7 days/week \\
\hline \multicolumn{2}{|l|}{ Second-line drugs } \\
\hline \multicolumn{2}{|l|}{ Aminoglycosides } \\
\hline Amikacin & 15 mg/kg/day 5-7 days/week \\
\hline Kanamycin & 15 mg/kg/day 5-7 days/week \\
\hline Capreomycin & 15 mg/kg/day 5-7 days/week \\
\hline \multicolumn{2}{|l|}{ Fluoroquinolones } \\
\hline Moxifloxacin & 400 mg/day \\
\hline Levofloxacin & 500-1,000 mg/day \\
\hline Ofloxacin & 400 mg twice daily \\
\hline Ciprofloxacin & 750 mg twice daily \\
\hline \multicolumn{2}{|l|}{ Thionamides } \\
\hline Ethionamide & 15-20 mg/kg/day \\
\hline Prothionamide & 15-20 mg/kg/day (maximum 1 g/day) \\
\hline Cycloserine & 15-20 mg/kg/day \\
\hline Para-aminosalicylic acid & $\begin{array}{l}\text { 8-12 g/day in 2-3 divided doses per day; in } \\
\text { children } 150 \text { mg/kg daily (max. dose } 8 \text { g); in adults } \\
150 \text { mg/kg daily (max. dose } 12 \text { g) g/day }\end{array}$ \\
\hline \multicolumn{2}{|l|}{ Third-line drugs } \\
\hline Clarithromycin & 500 mg twice daily \\
\hline Linezolid & 600 mg once daily \\
\hline Thioacetazone & 150 mg/day \\
\hline Imipenem & 1,000 mg IV twice daily \\
\hline Amoxicillin and clavulanate & $\begin{array}{l}\text { Amoxicillin 2,000 mg/day and clavulanate } \\
125 \text { mg/day twice daily }\end{array}$ \\
\hline \multicolumn{2}{|l|}{ Newer drugs } \\
\hline Bedaquiline & $\begin{array}{l}400 \text { mg/day for } 14 \text { days } \\
200 \text { mg/day } 3 \text { times a week for } 22 \text { weeks }\end{array}$ \\
\hline Delamanid & 100 mg twice daily for 24 weeks \\
\hline
\end{tabular}

IV = intravenous.

\section{Tuberculosis of the thyroid gland}

The thyroid gland is rarely involved directly by $M$. tuberculosis due to the intrinsic properties of the thyroid gland, which include the presence of colloid, high blood flow with excess bactericidal iodine, increased phagocytosis associated with hyperthyroidism, and extensive lymphatic and vascular supply. ${ }^{31}$

With current anti-TB regimens, the prevalence rate of thyroid involvement is $0.1-1 \%$, where the diagnosis was established after fine-needle aspiration and cytology (FNAC) of thyroid tissue sampled for any indication. ${ }^{32-34}$ Two publications, show thyroid involvement in $0.43 \%$ of FNAC samples in India and $0.6 \%$ from thyroidectomy specimens in Turkey. ${ }^{35,36}$ The exact prevalence of the infection is not known, and varies between 0.1 and $1.15 \% .{ }^{37}$ The
Table 4: Standard regimen for treatment of tuberculosis

\begin{tabular}{|c|c|}
\hline Intensive phase treatment & Continuation phase \\
\hline 2 months of HRZE & 4 or 7 months of HR \\
\hline
\end{tabular}

incidence of thyroid TB is $0.2 \%$ in chronic thyroiditis and $7-14 \%$ among those with miliary tuberculosis. ${ }^{38-40}$

The spread is usually via the hematogenous route, and very rarely can be directly from adjacent active laryngeal or lymph node foci. Primary involvement of the thyroid gland with TB has also been reported. ${ }^{41}$

Diagnosing thyroid gland TB may be difficult as thyroid function tests are rarely deranged and no specific symptoms are present. A few cases in initial stages can present with hyperthyroidism due to parenchymal damage and increased release of thyroid hormones. Significant destruction of the gland may later cause hypothyroidism.2-25 Most patients usually present with a painless thyroid nodule or diffuse goiter and lymphadenopathy with constitutional symptoms such as weight loss and fever of undetermined origin. Very rarely, a thyroid mass, thyroiditis, or an acute or cold abscess with or without a discharging sinus may be present. Caseation may or may not be present. Rarely, chronic fibrosing TB of the thyroid is seen with miliary disease. ${ }^{39}$ Histopathology shows presence of epithelioid granulomas, with central caseation, Langhans giant cells, and peripheral lymphocyte cuffing. ${ }^{2-2-44}$

One needs to differentiate tuberculous thyroiditis from bacterial thyroiditis. Although in patients with tuberculous thyroiditis the duration of symptoms is longer, they are less likely to have pain, thyroid tenderness, and fever, seen in bacterial infection. These patients can also develop dysphagia, dysphonia, or recurrent laryngeal nerve palsy due to compression of adjacent structures or fibrosis. Tuberculous thyroiditis is a diagnosis of exclusion for solitary cold thyroid nodules with normal thyroid function, especially in patients who are tuberculin-positive. On ultrasonography, tuberculous thyroiditis has a wide range of appearances from solid and heterogenous masses to cystic or hypoechoic lesions. ${ }^{30}$ This varied presentation makes it challenging to diagnose. CT and MRI findings are non-specific but may show evidence of intermediate signals on T1- and T2-weighted imaging or peripheral rim enhancement consistent with abscess. ${ }^{46,47}$

Cytology and microbiology using FNAC is preferred for excluding carcinoma or other granulomatous lesions like sarcoidosis, syphilis, and Hashimoto's

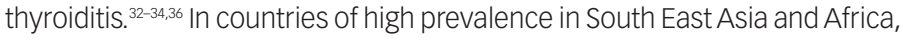
with a suspected diagnosis, treatment may be started in the presence of epithelioid granulomas with caseation, even in the absence of bacterial confirmation. ${ }^{32}$ Management includes a combination of surgery and anti-TB therapy. When a definitive diagnosis of thyroid involvement due to M. tuberculosis is made, sole treatment with standard anti-TB therapy, has resulted in favorable recovery of both the lesions and the abnormal thyroid function, if present. ${ }^{45}$ Treatment regimens are identical to those outlined in Table 4 for a duration of 6 months. Recurrence and failure rate with anti-TB therapy are about $1 \%$, due to drug resistance. Thyroxine supplementation is indicated in the presence of hypothyroidism. ${ }^{48}$ Surgery has a limited role in cases of unclear diagnosis or with suspicion of malignancy. In the presence of a tuberculous cold abscess, surgical drainage is required to avoid further destruction of thyroid tissue and consequent hypothyroidism. 
Table 5: Prevalence, spread, and features of endocrine and metabolic manifestations in tuberculosis

\begin{tabular}{|c|c|c|c|}
\hline Lesion & Incidence in \% & Spread & Manifestation \\
\hline $\begin{array}{l}\text { Addison's disease due } \\
\text { to TB }\end{array}$ & $7-20 \%$ of cases of Addison's disease ${ }^{9}$ & - Hematogenous spread & $\begin{array}{l}\text { - } \text { Malaise } \\
\text { - } \text { Weight loss } \\
\text { - Anorexia } \\
\text { - Orthostatic hypotension } \\
\text { - Hyperpigmentation }\end{array}$ \\
\hline Thyroid gland TB & $\begin{array}{l}0.1-1 \% \text { from FNAC of thyroid tissue } \\
\text { sampled for any indication }{ }^{32-34}\end{array}$ & $\begin{array}{l}\text { - Hematogenous dissemination } \\
\text { - Direct extension from an active laryngeal or } \\
\text { lymph node focus }\end{array}$ & $\begin{array}{l}\text { - Solitary cold abscess } \\
\text { - Diffuse goiter (often with caseation) } \\
\text { - } \text { Acute abscess } \\
\text { - Multiple lesions from miliary spread } \\
\text { - Chronic fibrosing TB }\end{array}$ \\
\hline Pituitary tuberculomas & $\begin{array}{l}0.15-4 \% \text { of all intracranial } \\
\text { space-occupying lesions }{ }^{59-61,123}\end{array}$ & $\begin{array}{l}\text { - } \text { - } \text { Dematogenous spread } \\
\text { sites - meningeal infection, sphenoid sinus, } \\
\text { cavernous sinus, skull }\end{array}$ & $\begin{array}{l}\text { - Headache } \\
\text { - } \text { Visual disturbances } \\
\text { - Hypofunction of the anterior pituitary gland } \\
\text { - Hypogonadotropic hypogonadism } \\
\text { - Hyperprolactinemia } \\
\text { - Central diabetes insipidus }\end{array}$ \\
\hline Hypothalamus & $\begin{array}{l}\text { Exact incidence of TB or involvement } \\
\text { with TBM not known }\end{array}$ & $\begin{array}{l}\text { - } \text { - } \text { Dematogenous spread } \\
\text { sites - meningeal infection, sphenoid sinus, } \\
\text { cavernous sinus, skull }\end{array}$ & $\begin{array}{l}\text { - Fever, headache } \\
\text { - Stiff neck } \\
\text { - Focal neurological deficits } \\
\text { - Behavioral changes } \\
\text { - Alterations in consciousness } \\
\text { - Neuroendocrine dysfunction - } \\
\text { hyperprolactinemia hypocorticism, } \\
\text { hypothyroidism, hypogonadism, SIADH }\end{array}$ \\
\hline $\begin{array}{l}\text { TBM with hypothalamic- } \\
\text { pituitary dysfunction }\end{array}$ & $1 \%$ of all cases of $\mathrm{TB}^{74}$ & Secondary to pulmonary or spinal TB & $\begin{array}{l}\text { - Fever, headache } \\
\text { - Stiff neck } \\
\text { - Focal neurological deficits } \\
\text { - } \text { Behavioral changes } \\
\text { - Alterations in consciousness } \\
\text { - } \text { Neuroendocrine dysfunction - } \\
\text { hyperprolactinemia hypocorticism, } \\
\text { - } \text { hypothyroidism, hypogonadism, SIADH } \\
\text { Cranial neuropathy (III, IV, VI) }\end{array}$ \\
\hline Hyponatremia & $11-43 \%$ of patients with active TB $^{123}$ & $\begin{array}{l}\text { Hematogenous spread to adrenal gland or } \\
\text { meninges }\end{array}$ & - Altered behavior or sensorium \\
\hline DM among patient with TB & $1.9-45 \%$ (median 16\%) $^{116}$ & \multirow[b]{2}{*}{$\begin{array}{l}\text { Risk/associated factors for TBDM comorbidity } \\
\text { - } \text { Family history of DM } \\
\text { - Pulmonary form of TB } \\
\text { - } \text { Positive sputum smear } \\
\text { - Urban > rural population } \\
\text { - Illicit drug use } \\
\text { - Sedentary lifestyle } \\
\text { - Low or high BMI } \\
\text { - HIV coinfection } \\
\text { - Pre-existing and long duration of DM } \\
\text { - Poor glycemic control } \\
\text { - History of liver cirrhosis and high blood } \\
\text { - } \text { pressure } \\
\text { cxtrapulmonary TB - low risk factor for TBDM }\end{array}$} & \multirow[b]{2}{*}{$\begin{array}{l}\text { - Generalized weakness } \\
\text { - Polyuria } \\
\text { - Polydipsia } \\
\text { - Fever } \\
\text { - Weight loss } \\
\text { - Cough } \\
\text { - Poor glycemic control with raised HbA1C }\end{array}$} \\
\hline $\begin{array}{l}\text { TB among patients with } \\
\text { DM }\end{array}$ & $0.38-14 \%$ (median 4.1) $)^{116}$ & & \\
\hline Hypercalcemia & $11-48 \%$ of patients with TB ${ }^{116}$ & $\begin{array}{l}\text { - Consequence of upregulated } 1 \alpha \text { hydroxylase } \\
\text { levels in macrophages with increased levels } \\
\text { of 1,25-dihydroxyvitamin D }\end{array}$ & $\begin{array}{l}\text { - Lethargy } \\
\text { - Nonspecific symptoms, such as constipation, } \\
\text { fatigue, and depression }\end{array}$ \\
\hline $\begin{array}{l}\text { *Thymus, parathyroid, } \\
\text { pancreas and pineal gland }\end{array}$ & - & - & - \\
\hline
\end{tabular}

*Tuberculosis of the thymus, parathyroid, pancreas, and pineal gland is very rare and no literature on its prevalence exists.

$B M I=$ body mass index; $D M=$ diabetes mellitus; FNAC = fine needle aspiration cytology; HbA1C= glycated hemoglobin; HIV = human immunodeficiency virus; SIADH = syndrome of inappropriate antidiuretic hormone secretion; TB = tuberculosis; TBDM = tuberculosis-diabetes mellitus; $T B M=$ tuberculous meningitis. 
Thyroid function abnormalities without gland involvement may rarely be seen in patients with active TB elsewhere. Following treatment initiation, there could be an elevation of serum free triiodothyronine and total triiodothyronine:; ${ }^{49}$ ith serum T4 and thyrotropin usually unaffected. ${ }^{50}$

Goiter and hypothyroidism can be seen with the use of ethionamide

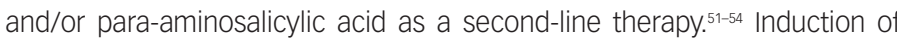
hepatic microsomal enzymes by rifampicin may enhance the extrathyroidal metabolism of thyroid hormones. ${ }^{55,56}$ These effects of anti-TB therapy, especially when rifampicin, ethionamide, and/or para-aminosalicylic acid are used, makes it prudent to monitor thyroid function along with liver function.

Euthyroid sick syndrome is the presence of abnormal thyroid function tests in patients with non-thyroidal illness, like TB, without pre-existing hypothalamic-pituitary and thyroid gland dysfunction. The incidence of euthyroid sick syndrome in TB ranges from $63-92 \%$ and serves as an indicator of severity of illness..$^{57}$ Cytokines such as tumor necrosis factor-alpha play a role in development of this syndrome. ${ }^{58}$ The abnormal thyroid function tests are completely reversible after recovery from TB.

\section{Tuberculosis of the pituitary gland}

Involvement of the pituitary gland is rare and its incidence has reduced from $4 \%$ of all intracranial lesions in the pre-antibiotic era ${ }^{59}$ to $0.15 \%$ with modern-day anti-TB therapy. ${ }^{60,61}$ The route of spread is usually hematogenous, though it may also be due to local extension from adjacent anatomical sites, namely the meninges, sphenoid sinus, cavernous sinus, and the skull.62 These inflammatory granulomatous lesions of the pituitary gland can behave as tumors being denoted as non-functioning sellar masses. The lesions can range in size from 2-12 $\mathrm{mm}$. They can also undergo caseation forming a pituitary abscess, or hemorrhagic infarction. ${ }^{63}$ Adjacent areas, such as the hypothalamus and pituitary stalk, also can be involved. It is very difficult to differentiate from the symptoms, whether the hypothalamic-pituitary dysfunction is due to direct pituitary or hypothalamic involvement or the involvement of both pituitary and hypothalamus. The clinical presentation varies; patients can be asymptomatic with subtle endocrine abnormalities or may present with fever, headache, and visual complaints, with or without selective hypopituitarism (seen in $20 \%$ of cases). ${ }^{64-66}$

Anterior pituitary dysfunction can occur later with or without central diabetes insipidus due to the compressive effect of the granulomatous lesion. ${ }^{67}$ The presentation may vary with age and severity of the disease: there could be growth retardation, hypogonadism, galactorrhea, amenorrhea, diabetes insipidus, and at times, panhypopituitarism. .2.25-69 In $^{2}$ males, hypopituitarism accompanied by hyperprolactinemia can result in decreased libido. ${ }^{63}$ In females, significant reduction in female sex hormones (progesterone and E2) results in disordered menstruation or amenorrhea. ${ }^{70}$ The most common abnormalities in pituitary function found in patients with tuberculous meningitis are hyperprolactinemia (49\%), cortisol insufficiency $(43 \%)$, hypothyroidism $(31 \%)^{, 11}$ and hypogonadotropic hypogonadism with low testosterone and gonadotropin levels $(29 \%)^{71-73}$ of the different abnormalities, growth hormone deficiency is the commonest sequalae. ${ }^{74}$ Timely diagnosis and administration of anti-TB therapy can reverse the endocrine dysfunction.

Hypothalamic-pituitary dysfunction may also occur in association with tuberculous meningitis which represents $1 \%$ of all cases of $\mathrm{TB}^{75}$ The pathological process in tuberculous meningitis results in formation of dense inflammatory exudates at the base of the brain involving the ambient cistern and the pontine cistern. ${ }^{76}$ Obliterative vasculitis with damage to hypothalamic-pituitary axis is also described. Both pathologies can result in hypothalamic-pituitary dysfunction with hormonal abnormalities, which improve in most patients with treatment of tuberculous meningitis. ${ }^{76}$ Tuberculous meningitis-related hypopituitarism is one of the most under-recognized and under-reported conditions. ${ }^{72}$

Pediatric tuberculous meningitis results in hypothalamic-pituitary dysfunction in $20 \%$ of patients, and can manifest even several years after recovery.7 The late endocrine sequalae in children include obesity, precocious puberty, diabetes insipidus, Frohlich syndrome, and growth retardation. ${ }^{78}$ Often, asymptomatic secondary hypoadrenalism due to pituitary dysfunction may remain undiagnosed in children, but may cause a fatal adrenal crisis during physical or psychological stress later in life. However overall, the incidence of hypothalamic-pituitary dysfunction in children is less frequent as compared to adults. ${ }^{77}$

Hypothalamic-pituitary dysfunction may also result from the weight loss and chronic illness that affect the hypothalamic gonadotropin-releasing hormone pulse generator. ${ }^{79}$ Disruption of hypothalamic-pituitary-gonadal axis can occur due to low leptin levels seen with weight loss and cachexia as a result of TB. ${ }^{80}$ With weight gain after anti-TB therapy, leptin levels rise and activate the hypothalamic-pituitary-gonadal axis with the return of normal function. ${ }^{81}$

Pituitary gland TB should be suspected in patients who have signs or symptoms of hypopituitarism with a history of TB elsewhere in the body. Assessment of endocrine function and radiological evaluation using MRI and CT scan will assist diagnosis, with the latter demonstrating calcification in the region of the sella turcica ${ }^{22}$ or the presence of intrasellar tumor. Thickening and nodularity of pituitary stalk, with or without extension into the sphenoid sinus, may be noted on CT or MRI. ${ }^{6983834}$ A TB pituitary abscess on MRI appears isointense to hypointense on T1-weighted images and hyperintense on T2-weighted images. But one must remember that, these signal characteristics are non-specific and can overlap those of pituitary adenomas and other inflammatory and granulomatous lesions. ${ }^{63}$ Tuberculous meningitis is usually diagnosed by lumbar puncture.

It is often difficult to histopathologically demonstrate caseating granulomas or acid-fast bacilli in pituitary disease or abscess. In most cases, the diagnosis is based on clinical features of hypopituitarism with MRI and biopsy, and if possible, confirmation with cultures should be done. The differential diagnoses of pituitary gland TB includes lymphocytic adenohypophysitis, sarcoidosis, Wegener's granulomatosis, idiopathic giant cell granulomatous hypophysitis, Takayasu's disease, Langerhans cell histiocytosis, syphilis, giant cell granuloma, Cogan's syndrome, and Crohn's disease. ${ }^{64}$

Treatment includes 2 months of rifampicin, isoniazid, pyrazinamide, and ethambutol followed by up to 10 months of rifampicin and isoniazid. ${ }^{85} \mathrm{It}$ is important to consider a lower efficacy of drugs due to the presence of the blood-brain barrier. Hormone replacement therapy may be necessary in some cases. ${ }^{86}$ Most lesions tend to resolve after standard anti-TB therapy (Table 5). ${ }^{87}$ Surgery is rarely indicated as a treatment modality, except for obtaining biopsies to confirm diagnosis in ambiguous cases. Trans-sphenoidal surgery may be necessary when there is radiological 
evidence of mass extension with established hypopituitarism. Surgery should be performed carefully to avoid excessive resection and to prevent hormonal deficiencies following surgery. Surgical findings include presence of a thickened hypophyseal stalk, a greyish firm mass with caseation, and a thickened dura. ${ }^{88,89}$

\section{Involvement of other endocrine glands Tuberculosis of the thymus}

Thymic involvement due to TB, though infrequent, can occur from direct infection. However, the thymic microenvironment also may be altered due to cytokine and immuno-hormonal alterations during active TB infection. This may contribute to a deficient control of infection and disease immunopathology. ${ }^{90}$ These patients present with non-specific general symptoms like fever, lethargy, loss of appetite, weight loss, retrosternal chest pain, cough, and progressive dyspnoea. ${ }^{91}$

\section{Tuberculosis of the parathyroid gland}

The parathyroid glands are not usually directly infected with M. tuberculosis. Pulmonary TB can be associated secondary hyperparathyroidism, which causes activation of osteoclasts, leading to increased bone resorption and consequently, hypercalcemia. This may be associated with or without excess production of 1,25-dihydroxyvitamin D3.92-94 In patients with concurrent vitamin D deficiency, hypercalcemia may not be present but may be unmasked after vitamin D supplementation. ${ }^{95}$ TB has been reported to be associated with persistent hypercalciuria, a low calcidiol level, and higher calcitriol level, which reverted to normal after anti-TB therapy (Table 5). ${ }^{96,97}$

Anti-TB therapy, particularly rifampicin and isoniazid, can decrease vitamin D levels by accelerated metabolism, and increase parathyroid hormone. Low vitamin D levels can mask hyperparathyroidism and hypercalcemia until anti-TB therapy is completed. ${ }^{98}$ Vitamin D supplementation may be needed.

\section{Tuberculosis of the pancreas}

TB of pancreas is very rare, even in regions of high TB prevalence, and occurs more commonly in males. ${ }^{99}$ Most cases of pancreatic TB are secondary to TB infection elsewhere in the body and the incidence may be higher with disseminated and miliary TB. Though most patients are asymptomatic, some may manifest with an abdominal mass and a cold abscess. ${ }^{100}$ Few may even present with obstructive jaundice, pain, fever, weight loss, or gastrointestinal bleed. Very limited data are available on pancreatic TB and its effects on endocrine and exocrine function of the pancreas. ${ }^{100}$

Biopsy or FNAC usually confirms the diagnosis of TB, with differential diagnoses being abscess or malignancy of pancreas. ${ }^{101-104}$ Ultrasonography, CT scan, and endosonography-guided biopsy are the recommended diagnostic techniques, as direct histopathological examination is the best way of diagnosing TB. The diagnosis of pancreatic TB should always be considered in young patients who present with non-specific symptoms and a pancreatic mass with peripancreatic lymphadenopathy on imaging studies. Most patients achieve complete cure with standard anti-TB therapy (Table 5). ${ }^{105}$

\section{Tuberculosis of the pineal gland}

TB of the pineal gland is rare and is more often seen in children. In patients with any TB, mean melatonin and 6-hydroxymelatonin sulphate concentrations are significantly lower than the controls subjects. ${ }^{106}$ Patients with pulmonary TB exhibit impairment of the circadian rhythm, which is more distinct in disseminated TB. ${ }^{107}$ Circadian rhythm is either misaligned or phase shifted, or is associated with reduced mean levels and amplitude of fluctuation of melatonin secretion. ${ }^{107}$

\section{Gonadal involvement}

In females, gonadal dysfunction is seen in about $56 \%$ of patients with genital TB. ${ }^{108}$ In males, isolated TB orchitis is very rare and is usually the result of direct extension from the epididymis. ${ }^{109}$ Anti-TB therapy can affect the metabolism of sex hormones with a moderate increase in estradiol and estrone levels. Though testosterone levels are unaltered, an increase in androstenedione levels has been noted. Among anti-TB drugs, rifampicin was responsible for the alteration in steroid hormone metabolism. ${ }^{110}$ Such interactions of anti-TB therapy with steroidal hormones in the female can result in contraception failure due to increased steroid degradation.

\section{Metabolic derangements in tuberculosis Syndrome of inappropriate antidiuretic hormone secretion with hyponatremia}

Hyponatremia is one of the most common electrolyte abnormalities observed due to inappropriate ectopic secretion of antidiuretic hormone in patients with pulmonary, miliary, and central nervous system-related TB. ${ }^{111,112}$ The exact mechanism of syndrome of inappropriate antidiuretic hormone secretion (SIADH) associated with pulmonary TB is poorly understood. ${ }^{112}$ Tubercular meningitis and the mass effect of tuberculoma on the pituitary stalk or pituitary gland itself and overt or subclinical adrenal insufficiency can also cause hyponatremia in patients with TB. ${ }^{74,113}$ In patients with HIV infection with TB, the incidence of hyponatremia is higher. ${ }^{114}$ Anti-TB drugs like ethionamide also cause SIADH and this may not be dose related. ${ }^{115}$ SIADH should be considered in the presence of hyponatremia with low serum osmolality, a normal acid-base state, urine osmolality >100 mOsm/kg, and urine sodium concentration $>40 \mathrm{mEq} / \mathrm{l}$.

\section{Tuberculosis and diabetes mellitus}

Patients with diabetes have an increased tendency to develop TB due to impaired cell-mediated immunity, renal failure, micronutrient deficiency, and pulmonary microangiopathy. ${ }^{116,117} \mathrm{~TB}$, which is a chronic infection, has a persistent inflammatory state, with an immune response associated with reactionary hyperglycemia, due to increased production of stress hormones like epinephrine, glucagon, cortisol, and growth hormone, which act synergistically. ${ }^{118}$ The occurrence and severity of stress hyperglycemia is related to duration of illness, severity of disease, degree of mycobacterial burden, and extent of lung cavitation. ${ }^{117,119}$ There is a solitary case report of TB of the pancreas resulting in brittle diabetes mellitus. $^{3}$

The presence of diabetes can alter the clinical presentation of TB and its outcome, in terms of delayed sputum/culture conversion, increased morbidity and mortality, and treatment failure. ${ }^{3,20}$ It is recommended to extend treatment to 9 months for patients with diabetes, cavitary disease, or delayed sputum clearance. The highest prevalence of diabetes mellitus among patients with TB is observed in Asia, North America, and Oceania; it is relatively high in Africa, and low in western countries. ${ }^{121}$ Factors associated with TB and diabetes mellitus comorbidity include sex, older age, urban residence, illicit drug use, alcoholism, cigarette smoking, 
sedentary lifestyle, obesity, HIV coinfection, hypertension, longstanding diabetes, poor glycemic control, pulmonary TB, and a family history of diabetes. ${ }^{121}$ Though data indicate that diabetes increases the risk of active $\mathrm{TB}$, the current understanding of biologic pathways between diabetes and risk of TB is greatly limited.

\section{Drug interaction with tuberculosis and diabetes mellitus}

Rifampicin induces an acute transient hyperglycemia due to its effect of augmenting intestinal absorption of glucose. ${ }^{122}$ It also induces the cytochrome P450 enzyme, which augments the hepatic metabolism of most oral hypoglycemic agents. ${ }^{122}$ Hence, patients with co-existing diabetes and TB should have their doses of oral anti-diabetic drugs adjusted upwards according to the plasma glucose concentration. An overdose of isoniazid may cause hyperglycemia, while in rare circumstances, diabetes may become difficult to control in patients on pyrazinamide. Rarely, hypoglycemia may be seen in patients on ethionamide.

\section{Disorders of calcium and vitamin D metabolism}

Granulomatous diseases like TB are associated with hypercalcemia due to increased tissue conversion of 25-hydroxyvitamin D3 to 25-dihydroxyvitamin D3 or calcitriol. ${ }^{3}$ Hypercalcemia also may be due to the increased intestinal absorption of calcium as a result of the production of 1,25-dihydroxyvitamin $D$ by macrophages. 1,25-dihydroxyvitamin $D$ produced by macrophages modulates the immune response by inducing expression of antimicrobial peptides, stimulation of the autophagy pathway, and acceleration of the resolution of inflammatory responses. ${ }^{123}$ However, some studies have shown no correlation between 1,25-dihydroxyvitamin D3 levels and serum calcium measurements. ${ }^{123}$ Though most often occurring with pulmonary $\mathrm{TB}$, hypercalcemia is occasionally seen in conjunction with extrapulmonary diseases like miliary TB, peritonitis, and osteomyelitis. The incidence is also higher in the presence of chronic kidney disease.

\section{Conclusion}

TB may directly or indirectly affect various endocrine glands including the adrenals, hypothalamus, pituitary, and thyroid, with the adrenal gland being most commonly affected. Extrapulmonary TB, such as that occurring in the endocrine glands, presents a diagnostic challenge due to its infrequent occurrence and presentation with nonspecific symptoms. This may result in diagnosis of the disease at an advanced stage, placing the patient at increased risk of morbidity and mortality. Thus, awareness about the occurrence of endocrine and metabolic dysfunction with TB needs to be emphasized among clinicians working in TB endemic regions. A high index of suspicion with a thorough evaluation, and if diagnosed, treatment with anti-TB therapy is necessary to improve quality of life and reduce mortality. The prevalence of, and endocrine and metabolic manifestations of, TB are summarised in Table 5 . $\square$
1. Parsons LM, Somoskövi Á, Gutierrez C, et al. Laboratory diagnosis of tuberculosis in resource-poor countries: challenges and opportunities. Clin Microbiol Rev. 2011;24:314-50.

2. World Health Organization. Global Tuberculosis Report 2019. Available at: www.who.int/tb/publications/global_report/en/ (accessed August 19, 2020)

3. Kibirige D. Endocrine dysfunction among adult patients with tuberculosis: an African experience. Indian J Endocrinol Metab. 2014;18:288-94

4. Matsumoto AM, Bremner WJ, Testicular Disorders. In: Melmed SH Polonsky KS, Larsen PR, Kronenberg HM (eds). Williams Textbook of Endocrinology 12th edition, New York: Sunders Elsevier, 2011;735-45.

5. Steingart KR, Ramsay A, Pai M. Commercial serological tests for the diagnosis of tuberculosis: do they work? Future Microbiol. 2007:2:355-9.

6. Pai M, Flores LL, Pai N, et al. Diagnostic accuracy of nucleic acid amplification tests for tuberculous meningitis: a systematic review and meta-analysis. Lancet Infect Dis. 2003;3:633-43.

7. Sterling TR, Njie G, Zenner D, et al. Guidelines for the treatment of latent tuberculosis infection: recommendations from the nationa tuberculosis controllers association and CDC, 2020. MMWR Recomm Rep. 2020:69:1-11.

8. Nahid P, Dorman SE, Alipanah N, et al. Official American Thoracic Society/Centers for Disease Control and Prevention/Infectious Diseases Society of America clinical practice guidelines: treatment of drug-susceptible tuberculosis. Clin Infect Dis. 2016;63:e147-95

9. Namikawa H, Takemoto Y, Kainuma S, et al. Addison's disease caused by tuberculosis with atypical hyperpigmentation and active pulmonary tuberculosis. Intern Med. 2017:56:1843-7.

10. Caroll TB, Aron DC, Findling JW, Tyrell JB, Glucocorticoids and adrenal androgens. In: Gardner DG, Shoback D (eds). Greenspan's Basic \& Clinical Endocrinology 9th edition, New York: McGraw-Hill, 2012;305

11. Lam KY, Lo CY. A critical examination of adrenal tuberculosis and a 28-year autopsy experience of active tuberculosis. Clin Endocrinol (Oxf). 2001; 54:633-9.

12. Kannan CR. Addison's disease. In: Kannan CR (ed), The Adrenal Gland, Boston: Springer, 1988:31-96.

13. Keleştimur F, Ünlü Y, Özesmi M, Tolu I. A hormonal and radiological evaluation of adrenal gland in patients with acute or chronic pulmonary tuberculosis. Clin Endocrinol (Oxf) 1994;41:53-6.

14. Upadhyay J, Sudhindra P, Abraham G, Trivedi N. Tuberculosis of the adrenal gland: a case report and review of the literature of infections of the adrenal gland. Int J Endocrinol. 2014:876037.

15. Kelestimur F. The endocrinology of adrenal tuberculosis: the effects of tuberculosis on the hypothalamo-pituitary-adrenal axis and adrenocortical function. J Endocrinol Invest. 2004;27:380-6.

16. Stewart PM, Krone NP, The Adrenal Cortex. In: Melmed S, Polonsky KS, Larsen PR, Kronenberg HM (eds). Williams Textbook of Endocrinology 12th edition, Philadelphia: Saunders, 2011;516.
17. Bornstein SR. Predisposing factors for adrenal insufficiency. $N$ Engl J Med. 2009;360:2328-39.

18. Huang $\mathrm{YC}$, Tang $\mathrm{YL}$, Zhang $\mathrm{XM}$, et al. Evaluation of primary adrenal insufficiency secondary to tuberculous adrenalitis with computed tomography and magnetic resonance imaging: current status. World J Radiol. 2015:7:336-42.

19. Buxi TB, Vohra RB, Byotra SP, et al. CT in adrenal enlargement due to tuberculosis: a review of literature with five new cases. Clin Imaging. 1992;16:102-8.

20. Doppman JL, Gill JJ, Nienhuis AW, et al. CT findings in Addison's disease. J Comput Assist Tomogr. 1982;6:757-61.

21. Vita JA, Silverberg SJ, Goland RS, et al. Clinical clues to the cause of Addison's disease. Am J Med. 1985:78:461-6.

22. Wang $L$, Yang J. Tuberculous Addison's disease mimics malignancy in FDG-PET images. Intern Med. 2008:47:1755-6.

23. Lack EE. Embryology, developmental anatomy, and selected aspects of non-neoplastic pathology. In: Lack EE (ed), Pathology of the Adrenal Glands, London: Churchill Livingstone, 1990;14:1-74.

24. Esteban NV, Loughlin T, Yergey AL, et al. Daily cortisol production rate in man determined by stable isotope dilution/mass spectrometry. J Clin Endocrinol Metab. 1991;72:39-45.

25. Crown A, Lightman S. Management of patients with glucocorticoid deficiency. Nat Clin Pract Endocrinol Metab. 2005;1:62-3.

26. Crown A, Lightman S. Why is the management of glucocorticoid deficiency still controversial: a review of the literature. Clin Endocrinol (Oxf). 2005;63:483-92.

27. Groves RW, Toms GC, Houghton BJ, Monson JP. Corticosteroid replacement therapy: twice or thrice daily? J R Soc Med. 1988;81:514-6

28. McAllister WA, Thompson PJ, Al-Habet SM, Rogers HJ. Rifampicin reduces effectiveness and bioavailability of prednisolone. $\mathrm{Br} \mathrm{Med}$ $J$ (Clin Res Ed). 1983:286:923-5.

29. Bhatia E, Jain SK, Gupta RK, Pandey R. Tuberculous Addison's disease: lack of normalization of adrenocortical function after anti-tuberculous chemotherapy. Clin Endocrinol (Oxf). 1998:48:355-9

30. Al-Mamari A, Balkhair A, Gujjar A, et al. A case of disseminated tuberculosis with adrenal insufficiency. Sultan Qaboos Univ Med $\mathrm{J}$. 2009;9:324-7.

31. Chuang TJ, Liu JS, Hung YJ, Hsieh CH. Thyroid tuberculosis. QJM. 2015;10:47-8.

32. Majid U, Islam N. Thyroid tuberculosis: a case series and a review of the literature. J Thyroid Res. 2011:59864

33. Baidya A, Singha A, Bhattacharjee R, Dalal BS. Tuberculosis of the thyroid gland: two case reports. Oxford Med Case Reports. 2015:262-4

34. Ortiz-Flores A, Gioia F, Montánez-Fernández L, Santacruz E, Martín-Dávila P, Pian-Arias H, Botella-Carretero JI. Incidental finding of a primary thyroid tuberculosis. Oxf Med Case Reports. 2017;2017:0mx022.

35. Gupta N, Sharma K, Barwad A, et al. Thyroid tuberculosisrole of PCR in diagnosis of a rare entity. Cytopathology. 2011;22:392-6
36. Ozekinci S, Mizrak B, Saruhan G, Senturk S. Histopathologic diagnosis of thyroid tuberculosis. Thyroid. 2009;19:983-6.

37. Kataria SP, Tanwar P, Singh S, Kumar S. Primary tuberculosis of the thyroid gland: a case report. Asian Pac J Trop Biomed. 2012:2:839-40

38. Simkus A. Thyroid tuberculosis. Medicina 2004:40:201-4

39. Chaudhary A, Nayak B, Guleria S, Arora R, Gupta R, Sharma MC Tuberculosis of the thyroid presenting as multinodular goiter with hypothyroidism: a rare presentation. Indian I Pathol Microbiol. 2010;53:579

40. Silva BP, Amorim EG, Pavin EJ, Martins AS, Matos PS, ZantutWittmann DE. Primary thyroid tuberculosis: a rare etiology of hypothyroidism and anterior cervical mass mimicking carcinoma. Arquivos Brasileiros de Endocrinologia \& Metabologia. 2009:53:475-8.

41. Pazaitou K, Chrisoulidou A, Ginikopoulou E, Angel J, Destouni C, Vainas I. Primary tuberculosis of the thyroid gland: report of three cases. Thyroid. 2002;12:1137-40.

42. Barnes P, Weatherstone R. Tuberculosis of the thyroid: two case reports. Br J Dis Chest. 1979;73:187-91.

43. Johnson AG, Phillips ME, Thomas RJ. Acute tuberculous abscess of the thyroid gland. Br J Surg. 1973;60:668-9.

44. Kapoor VK, Subramani K, Das SK, et al. Tuberculosis of the thyroid gland associated with thyrotoxicosis. Postgrad Med $\rfloor$ 1985;61:339

45. Nieuwland Y, Tan KY, Elte JW. Miliary tuberculosis presenting with thyrotoxicosis. Postgrad Med J. 1992;68:677-9.

46. Kang BC, Lee SW, Shim SS, et al. US and CT findings of tuberculosis of the thyroid: three case reports. Clin Imaging. 2000;24:283-6.

47. Madhusudhan KS, Seith A, Khadgawat R, et al. Tuberculosis of the thyroid gland: magnetic resonance imaging appearances. Singapore Med I. 2009:50:e235-8.

48. El Malki HO, Mohsine R, Benkhraba K, et al. Thyroid tuberculosis: diagnosis and treatment. Chemotherapy. 2006;52:46-9.

49. Ilias I, Tselebis A, Boufas A, et al. Pulmonary tuberculosis and its therapy do not significantly affect thyroid function tests. Int I Clin Pract. 1998;52:227-8.

50. Hill AR, Schmidt MF, Schussler GC. Rapid changes in thyroid function tests upon treatment of tuberculosis. Tuber Lung Dis. 1995;76:223-9.

51. Munkner T. Studies on goitre due to para-aminosalicylic acid Scand J Respir Dis. 1969;50:212-26.

52. Chhabra N, Gupta N, Aseri ML, et al. Analysis of thyroid function tests in patients of multidrug resistance tuberculosis undergoing treatment. J Pharmacol Pharmacother. 2011;2:282-5.

53. Munivenkatappa $S$, Anil S, Naik B, et al. Drug-induced hypothyroidism during anti-tuberculosis treatment of multidrug resistant tuberculosis: notes from the field. J Tuberc Res. 2016:4:105-10.

54. Thee S, Zöllner EW, Willemse M, et al. Abnormal thyroid function tests in children on ethionamide treatment. Int J Tuberc Lung Dis. 2011;15:1191-3.

55. Ohnhaus EE, Studer H. A link between liver microsomal enzyme 
activity and thyroid hormone metabolism in man. Br J Clin Pharmacol. 1983;15:71-6.

56. Kim DL, Song KH, Lee JH, et al. Rifampin-induced hypothyroidism without underlying thyroid disease. Thyroid. 2007;17:793-5.

57. Chow CC, Mak TW, Chan $\mathrm{CH}$, Cockram CS. Euthyroid sick syndrome in pulmonary tuberculosis before and after treatment. Ann Clin Biochem. 1995:32:385-91.

58. Rasmussen AK. Cytokine actions on the thyroid gland. Dan Med Bull. 2000;47:94-114.

59. Slavin RE, Walsh TJ, Pollack AD. Late generalized tuberculosis: a clinical pathologic analysis and comparison of 100 cases in the preantibiotic and antibiotic eras. Medicine (Baltimore). 1980;59:352-66

60. Glezer A, Paraiba DB, Bronstein MD. Rare sellar lesions. Endocrinol Metab Clin North Am. 2008:37:195-211.

61. Majumdar K, Barnard M, Ramachandra S, et al. Tuberculosis in the pituitary fossa: a common pathology in an uncommon site. Endocrinol Diabetes Metab Case Rep. 2014;2014:140091.

62. Kirshbaum JD, Levy HA. Tuberculoma of hypophysis with insufficiency of anterior lobe: A clinical and pathologic study of two cases. Arch Intern Med (Chic). 1941;68:1095-104.

63. Mascarenhas JV, Ayyar SV. Tuberculosis of the sella masquerading as pituitary adenoma. J Clin Sci Res. 2013:2:42-4.

64. Berger SA, Edberg SC, David G. Infectious disease in the sella turcica. Rev Infect Dis. 1986;8:747-55.

65. Ranjan A, Chandy MJ. Intrasellar tuberculoma. Br J Neurosurg 1994;8:179-85.

66. Rickards AG, Harvey PW. Giant-cell granuloma and the other pituitary granulomata. Q J Med. 1954;23:425-39.

67. Delsedime M, Aguggia M, Cantello R, et al. Isolated hypophyseal tuberculoma: case report. Clin Neuropathol. 1988;7:311-3.

68. Brooks MH, Dumlao JS, Bronsky D, Waldstein SS. Hypophysial tuberculoma with hypopituitarism. Am J Med. 1973;54:777-81.

69. Srisukh S, Tanpaibule T, Kiertiburanakul S, et al. Pituitary tuberculoma: a consideration in the differential diagnosis in a patient manifesting with pituitary apoplexy-like syndrome. IDCases. 2016;5:63-6.

70. Magdy DM, AZouz AM, El Zohne RA. Alteration of female sex hormones and menstrual pattern among women infected with pulmonary tuberculosis. Egypt I Chest Dis Tuberc. 2019;68:146-9.

71. Pekic S, Miljic D, Popovic V. Infections of the hypothalamicpituitary region [Updated 2018 Oct 7]. In: Feingold KR, Anawalt B, Boyce A, et al. (eds), editors. Endotext [Internet]. South Dartmouth (MA): MDText.com, Inc.; 2000. Available at: www.ncbi.nlm.nih.gov/ books/NBK532083/ (accessed August 19, 2020).

72. Sonkar SK, Kumar S, Singh NK. Panhypopituitarism - an unusual presenation of tuberculous meningitis. Indian J Tuberc. 2019:66:427-9

73. Dhanwal DK, Vyas A, Sharma A, Saxena A. Hypothalamic pituitary abnormalities in tubercular meningitis at the time of diagnosis. Pituitary. 2010;13:304-10

74. Lam KS, Sham MM, Tam SC, et al. Hypopituitarism after tuberculous meningitis in childhood. Ann Intern Med. 1993;118:701-6.

75. Santana MF, João GA, Lacerda MV, Ferreira LC. Diabetes insipidus secondary to tuberculous meningoencephalitis with hypothalamic involvement extending to the hypophysis: a case report. Rev SOC Bras Med Trop. 2018;51:865-7.

76. Mohammed H, Goyal MK, Dutta P, et al. Hypothalamic and pituitary dysfunction is common in tubercular meningitis: a prospective study from a tertiary care center in Northern India. J Neurol Sci. 2018;395:153-8.

77. Giavoli C, Tagliabue C, Profka E, et al. Evaluation of pituitary function after infectious meningitis in childhood. BMC Endocr Disord. 2014;14:80
78. Aulakh R, Chopra S. Pediatric tubercular meningitis: a review J Pediatr Neurosci. 2018;13:373-82.

79. Silveira LF, Latronico AC. Approach to the patient with hypogonadotropic hypogonadism. I Clin Endocrinol Metab. 2013:98:1781-8

80. Mexitalia M, Dewi YO, Pramono A, Anam MS. Effect of tuberculosis treatment on leptin levels, weight gain, and percentage body fat in Indonesian children. Korean J Pediatr. 2017:60:118-23.

81. Blüher $S$, Mantzoros CS. The role of leptin in regulating neuroendocrine function in humans. I Nutr. 2004;134:2469S-74S

82. Sherman BM, Gorden P, di Chiro G. Postmeningitic selective hypopituitarism with suprasellar calcification. Arch Intern Med. 1971:128:600-4.

83. Sharma MC, Arora R, Mahapatra AK, et al. Intrasellar tuberculoma-an enigmatic pituitary infection: a series of 18 cases. Clin Neurol Neurosurg. 2000;102:72-7.

84. Stalldecker G, Diez S, Carabelli A, et al. Pituitary stalk tuberculoma. Pituitary. 2002;5:155-62.

85. Stop TB Initiative (World Health Organization). In: World Health Organization, Treatment of Tuberculosis: Guidelines, Geneva: World Health Organization, 2010

86. Husain N, Husain M, Rao P. Pituitary tuberculosis mimicking idiopathic granulomatous hypophysitis. Pituitary. 2008; 11:313-5.

87. Dutta P, Bhansali A, Singh P, Bhat MH. Suprasellar tubercular abscess presenting as panhypopituitarism: a common lesion in an uncommon site with a brief review of literature. Pituitary. 2006:9:73-7.

88. Ghosh S, Chandy MJ. Intrasellar tuberculoma. Clin Neurol Neurosurg. 1992;94:251-2.

89. Taparia SC, Tyagi G, Singh AK, et al. Sellar tuberculoma. J Neurol Neurosurg Psychiatry. 1992;55:629.

90. D'Attilio L, Santucci N, Bongiovanni B, et al. Tuberculosis, the disrupted immune-endocrine response and the potential thymic repercussion as a contributing factor to disease physiopathology. Front Endocrinol (Lausanne). 2018;9:214.

91. Pillai KR, Prakash M, Pai MR. Clinicopathological characteristics of thymic tuberculosis-a rare entity. J Clin Diagn Res. 2016;10:ED13-5.

92. Davies PD, Brown RC, Woodhead JS. Serum concentrations of vitamin $\mathrm{D}$ metabolites in untreated tuberculosis. Thorax. 1985;40:187-90.

93. Chan TY, Poon P, Pang J, et al. A study of calcium and vitamin D metabolism in Chinese patients with pulmonary tuberculosis. J Trop Med Hyg. 1994;97:26-30

94. Singh HP, Narang V, Sood N, Puri H. Parathyroid adenoma associated with granulomatous inflammation: a curious cause of hypercalcaemia. J Clin Diagn Res. 2016;10:ED21-2.

95. Davies PD, Church HA, Brown RC, Woodhead JS. Eur J Respir Dis. 1987;71:341-4

96. Martinez ME, Gonzalez J, Sanchez-Cabezudo MJ, et al. Evidence of absorptive hypercalciuria in tuberculosis patients. Calcif Tissue Int. 1993;53:384-7.

97. Martinez ME, Gonzalez J, Sanchez-Cabezudo MJ, et al. Remission of hypercalciuria in patients with tuberculosis after treatment. Calcif Tissue int 1996:59:17-20

98. Kovacs CS, Jones G, Yendt ER. Primary hyperparathyroidism masked by antituberculous therapy-induced vitamin $D$ deficiency. Clin Endocrinol (Oxf). 1994;41:831-6.

99. Chaudhary P, Bhadana U, Arora MP. Pancreatic tuberculosis. Indian J Surg. 2015;77:517-24

100. Panic N, Maetzel H, Bulajic M, et al. Pancreatic tuberculosis: A systematic review of symptoms, diagnosis and treatment. United European Gastroenterol J. 2020;8:396-402.

101. Chandraskasa KL, Iyer SK, Stanek AE, et al. Pancreatic tuberculosis mimicking carcinoma. Gastrointest Endosc. 1985;31:386-8. 102. Stambler JB, Klibaner MI, Blis CHN, et al. Tuberculosis abscess of the pancreas. Gastroenterol. 1982;83:992-5.

103. Mignal F, Beltran J, Sabas JA, et al. Tuberculosis pancreatic abscess. Br J Surg. 1985:72:438.

104. Liang $X$, Huang $X$, Yang $Q$, He J. Calcified peripancreatic lymph nodes in pancreatic and hepatic tuberculosis mimicking pancreatic malignancy: a case report and review of literature. Medicine (Baltimore). 2018;97:e12255.

105. Chaudhary P, Bhadana U, Arora MP. Pancreatic tuberculosis. Indian J Surg. 2015;77:517-24

106. Ozkan E, Yaman H, Cakir E, et al. Plasma melatonin and urinary 6-hydroxymelatonin levels in patients with pulmonary tuberculosis. Inflammation. 2012:35:1429-34.

107. Karimdzhanov IA, Ginzburg VS, Ubaìdullaev AM. Circadian rhythm of pituitary-adrenal and pituitary-gonadal systems in patients with pulmonary tuberculosis. Probl Tuberk. 1993;3:53-6.

108. Solov'eva IP. State of the endometrium in patients with female genital tuberculosis according to biopsy data. Probl Tuberk. 1989;5:53-6.

109. Michaelides M, Sotiriadis C, Konstantinou D, et al. Tuberculous orchitis US and MRI findings. Correlation with histopathological findings. Hippokratia. 2010:14:297-9.

110. Lonning PE, Bakke P, Thorsen T, et al. Plasma levels of estradiol, estrone, estrone sulfate and sex hormone binding globulin in patients receiving rifampicin. J Steroid Biochem. 1989;33:631-5.

111. Jafari NJ, Izadi M, Sarrafzadeh F, et al. Hyponatremia due to pulmonary tuberculosis: review of 200 cases. Nephrourol Mon. 2013:5:687-91

112. Lee $\mathrm{P}, \mathrm{HO}$ KK. Hyponatremia in pulmonary TB: evidence of ectopic antidiuretic hormone production. Chest. 2010;137:207-8.

113. Jacobi J, Schnellhardt S, Kulschewski A, et al. An unusual case of hyponatraemia. Nephrol Dial Transplant. 2010;25:998-1001.

114. Smith MB, Boyars MC, Veasey S, Woods GI. Generalized tuberculosis in the acquired immune deficiency syndrome. Arch Pathol Lab Med. 2000;124:1267-74.

115. Nakashita T, Motojima S. Case of SIADh caused by ethionamide in a patient with pulmonary tuberculosis. Kekkaku. 2006:81:731-5

116. Magee MJ, Salindri AD, Kyaw NT, et al. Stress hyperglycemia in patients with tuberculosis disease: epidemiology and clinical implications. Curr Diab Rep. 2018;18:71.

117. Magee MJ, Salindri AD, Gujral UP, et al. Convergence of noncommunicable diseases and tuberculosis: a two-way street? Int J Tuberc Lung Dis. 2018:22:1258-68.

118. Kornfeld $\mathrm{H}$, West $\mathrm{K}$, Kane $\mathrm{K}$, et al. High prevalence and heterogeneity of diabetes in patients with TB in South India: a report from the effects of diabetes on tuberculosis severity (EDOTS) study. Chest. 2016;149:1501-8.

119. Saluja SS, Ray S, Pal S, et al. Hepatobiliary and pancreatic tuberculosis: a two decade experience. BMC surg. 2007;7:10

120. Faurholt-Jepsen D, Range N, PrayGod G, et al. Diabetes is a strong predictor of mortality during tuberculosis treatment: $A$ prospective cohort study among tuberculosis patients from Mwanza, Tanzania. Trop Med Int Health. 2013:18:822-9.

121. Workneh MH, Bjune GA, Yimer SA. Prevalence and associated factors of tuberculosis and diabetes mellitus comorbidity: a systematic review. PloS One. 2017;12:e0175925.

122. Park JY, Kim KA, Park PW, et al. Effect of rifampin on the pharmacokinetics and pharmacodynamics of gliclazide. Clin Pharmacol Ther. 2003;74:334-40.

123. Vinnard C, Blumberg EA. Endocrine and metabolic aspects of tuberculosis. Microbiol Spectr. 2017:515-27. 